\title{
Darlehen mit niedrigen Zinsen bei einer Geschäftsbeziehung zum Ausland
}

Werden Einkünfte eines StPfl. aus einer Geschäftsbeziehung zum Ausland mit einer ihm nahe stehenden Person dadurch gemindert, dass er seiner Einkünfteermittlung andere Bedingungen zugrunde legt, als sie voneinander unabhängige Dritte unter gleichen oder vergleichbaren Verhältnissen vereinbart hätten (Fremdvergleichsgrundsatz), sind seine Einkünfte unbeschadet anderer Vorschriften so anzusetzen, wie sie unter den voneinander unabhängigen Dritten vereinbarten Bedingungen angefallen wären (§ $1 \mathrm{Abs} .1 \mathrm{AStG})$.

Wird ein Darlehen unter den Voraussetzungen des $§ 1$ Abs. 1 AStG zu unangemessen niedrigen Zinsen in das Ausland gewährt, so muss für die Ermittlung des Korrekturbetrages festgestellt werden, in welcher Währung das Darlehen zurückgezahlt werden soll. Im Übrigen muss sich die Erhöhung nach dem AStG daran orientieren, dass sich Darlehensgläubiger und Darlehensschuldner im Zweifel die Spanne zwischen banküblichen Habenund Sollzinsen teilen (BFH 19.01.1994 I R 93/93, BStB1. 1994 II, 725, BFHE 174, 61). 